University of Nebraska - Lincoln

DigitalCommons@University of Nebraska - Lincoln

2017

\title{
Defining Ecological Drought for the Twenty-First Century
}

\author{
Shelley D. Crausbay \\ University of California, Santa Barbara, shelley@csp-inc.org \\ Aaron R. Ramirez \\ University of California, Santa Barbara, ramireza@reed.edu \\ Shawn L. Carter \\ USGS \\ Molly S. Cross \\ Wildlife Conservation Society \\ Kimberly R. Hall \\ The Nature Conservancy
}

See next page for additional authors

Follow this and additional works at: https://digitalcommons.unl.edu/natrespapers

Part of the Natural Resources and Conservation Commons, Natural Resources Management and Policy Commons, and the Other Environmental Sciences Commons

Crausbay, Shelley D.; Ramirez, Aaron R.; Carter, Shawn L.; Cross, Molly S.; Hall, Kimberly R.; Bathke, Deborah J.; Betancourt, Julio L.; Colt, Steve; Cravens, Amanda E.; Dalton, Melinda S.; Dunham, Jason B.; Hay, Lauren E.; Hayes, Michael J.; McEvoy, Jamie; McNutt, Chad A.; Moritz, Max A.; Nislow, Keith H.; Raheem, Nejem; and Sanford, Todd, "Defining Ecological Drought for the Twenty-First Century" (2017). Papers in Natural Resources. 784.

https://digitalcommons.unl.edu/natrespapers/784

This Article is brought to you for free and open access by the Natural Resources, School of at DigitalCommons@University of Nebraska - Lincoln. It has been accepted for inclusion in Papers in Natural Resources by an authorized administrator of DigitalCommons@University of Nebraska - Lincoln. 


\section{Authors}

Shelley D. Crausbay, Aaron R. Ramirez, Shawn L. Carter, Molly S. Cross, Kimberly R. Hall, Deborah J.

Bathke, Julio L. Betancourt, Steve Colt, Amanda E. Cravens, Melinda S. Dalton, Jason B. Dunham, Lauren

E. Hay, Michael J. Hayes, Jamie McEvoy, Chad A. McNutt, Max A. Moritz, Keith H. Nislow, Nejem Raheem, and Todd Sanford 


\title{
Defining Ecological Drought for the Twenty-First Century
}

\author{
Shelley D. Crausbay, Aaron R. Ramirez, Shawn L. Carter, Molly S. Cross, Kimberly R. Hall, \\ Deborah J. Bathke, Julio L. Betancourt, Steve Colt, Amanda E. Cravens, Melinda S. Dalton, \\ jason B. Dunham, lauren E. Hay, Michael J. Hayes, Jamie Mcevor, Chad A. McNutt, \\ Max A. Moritz, Keith H. Nislow, Nejem Raheem, and Todd Sanford
}

THE RISING RISK OF DROUGHT. Droughts of the twenty-first century are characterized by hotter temperatures, longer duration, and greater spatial extent, and are increasingly exacerbated by human demands for water. This situation increases the vulnerability of ecosystems to drought, including a rise in drought-driven tree mortality globally (Allen et al. 2015) and anticipated ecosystem transformations from one state to another-for example, forest to a shrubland (Jiang et al. 2013). When a drought drives changes within ecosystems, there can be a ripple effect through human communities that depend on those ecosystems for critical goods and services (Millar and Stephenson 2015). For example, the "Millennium Drought" (2002-10) in Australia caused unanticipated losses to key services provided by hydrological ecosystems in the Murray-Darling basin-including air quality regulation, waste treatment, erosion prevention, and recreation. The costs of these losses exceeded AUD $\$ 800$ million, as resources were spent to replace these services and adapt to new drought-impacted ecosystems (Banerjee et al. 2013). Despite the high costs to both nature and people, current drought research, management, and policy perspectives often fail to evaluate how drought affects ecosystems and the "natural capital" they provide to human communities. Integrating these human and natural dimensions of drought is an essential step toward addressing the rising risk of drought in the twenty-first century.

Part of the problem is that existing drought definitions describing meteorological drought impacts (agricultural, hydrological, and socioeconomic) view drought through a human-centric lens and do not fully address the ecological dimensions of drought.
AfFiliations: CRAUSBAY AND RAMIREZ*-National Center for Ecological Analysis and Synthesis, University of California, Santa Barbara, Santa Barbara, California; CARTER-National Climate Change and Wildlife Science Center, U.S. Geological Survey, Reston, Virginia; Cross-Wildlife Conservation Society, Bozeman, Montana; HaLL-North America Region, The Nature Conservancy, Haslett, Michigan; BATHKe AND HAYES-National Drought Mitigation Center, University of Nebraska-Lincoln, Lincoln, Nebraska; BetancourT-National Research Program, U.S. Geological Survey, Reston, Virginia; Colt-Business Administration Program, Alaska Pacific University, Anchorage, Alaska; Cravens-Fort Collins Science Center, U.S. Geological Survey, Fort Collins, Colorado; DALTON-Georgia Water Science Center, U.S. Geological Survey, Atlanta, Georgia; DunHAMForest and Rangeland Ecosystem Science Center, U.S. Geological Survey, Corvallis, Oregon; HAY-Denver Federal Center, U.S. Geological Survey, Denver, Colorado; McEvor-Department of Earth Sciences, Montana State University, Bozeman, Montana;
McNutT-National Integrated Drought Information System Program Office, Joint Office for Science Support, University Corporation for Atmospheric Research, Boulder, Colorado; MORITZ-Department of Environmental Science, Policy, and Management, University of California, Berkeley, Berkeley, California; NisLow-Northern Research Station, U.S. Forest Service, University of Massachusetts, Amherst, Massachusetts; RAHEEM-Department of Marketing Communication, Emerson College, Boston, Massachusetts; SANFORD-Climate Central, Boulder, Colorado

* These authors contributed equally CORRESPONDING AUTHORS: Shelley D. Crausbay, shelley @csp-inc.org; Aaron R. Ramirez, ramireza@reed.edu

DOI:I0.II75/BAMS-D-16-0292.I

(C)2017 American Meteorological Society

For information regarding reuse of this content and general copyright information, consult the AMS Copyright Policy. 


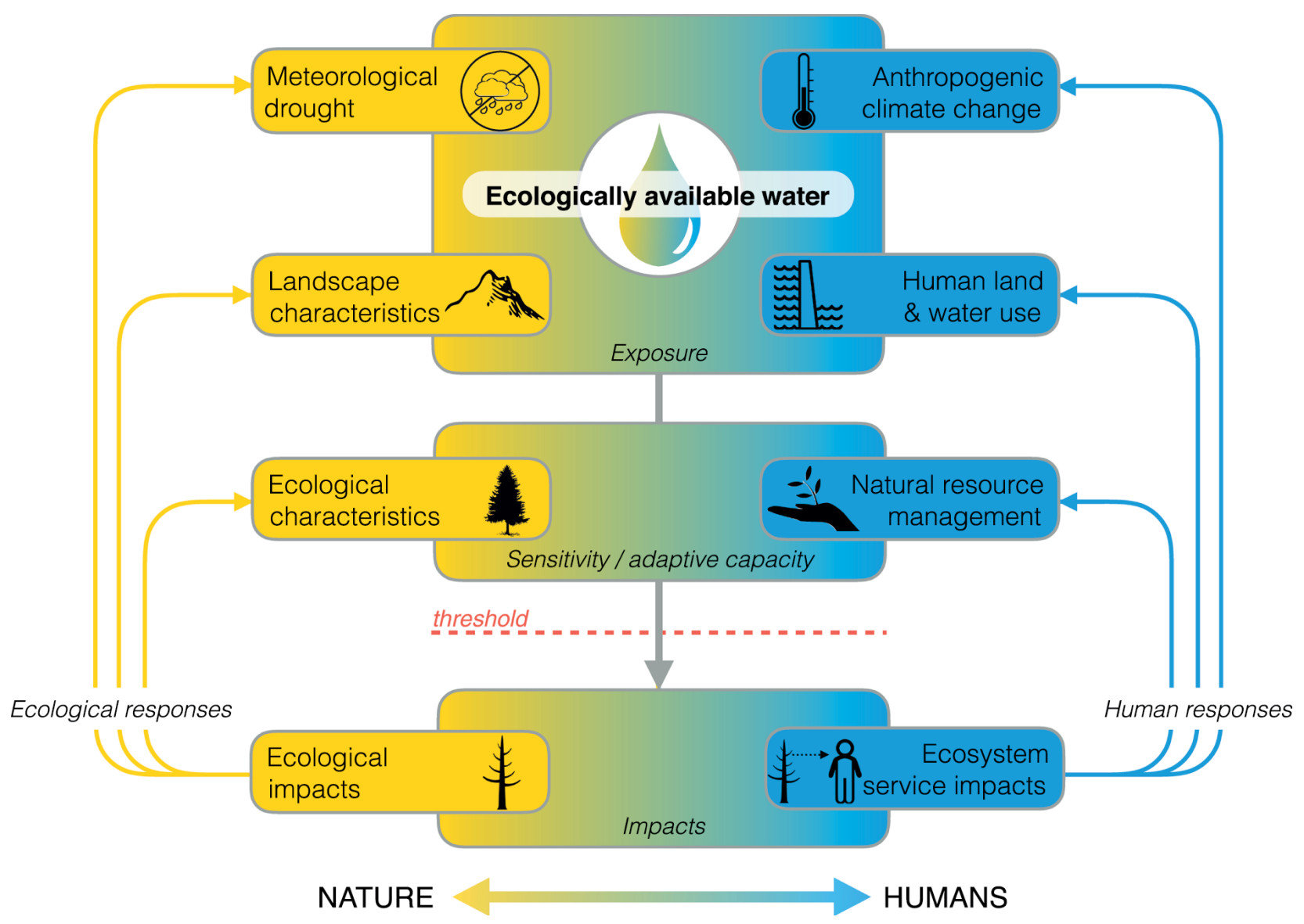

Fig. I. Conceptual diagram of ecological drought in the twenty-first century. This diagram illustrates the key drivers of drought vulnerability and impacts in coupled natural-human systems. Vulnerability = exposure + sensitivity + adaptive capacity. Curved arrows indicate feedbacks where ecological responses and changes in human behavior or institutions can alter ecological drought vulnerability. The yellow-blue color gradient represents the continuum of coupled natural-human systems.

Redmond (2002) posed the question, "Like the tree falling in the forest, does drought occur if there is no human to record or experience it?" (p. 1144). Redmond later answered his own question by arguing that drought indeed "extends to vegetation and ecosystems" (p. 1144). Yet, ecosystem responses to drought remain largely absent from many drought-planning efforts, resulting in debates that often pit the water needs of humans against the needs of ecosystems. Meanwhile, rapidly expanding human populations and anthropogenic climate change increase pressure on ecological water supplies and alter ecosystems in ways that can increase their vulnerability to drought, with real consequences for human communities through loss of ecosystem services. To prepare us for the rising risk of drought in the twenty-first century, we need to reframe the drought conversation by underscoring the value to human communities in sustaining ecosystems and the critical services they provide when water availability dips below critical thresholds. In particular, we need to define a new type of drought-ecological drought-that integrates the ecological, climatic, hydrological, socioeconomic, and cultural dimensions of drought.

To this end, we define the term ecological drought as an episodic deficit in water availability that drives ecosystems beyond thresholds of vulnerability, impacts ecosystem services, and triggers feedbacks in natural and/or human systems. We support this definition with a novel, integrated framework for 
ecological drought that is organized along two dimensions - the components of vulnerability (exposure + sensitivity/adaptive capacity) and a continuum from human to natural factors (Fig. 1). The purpose of this framework is to help guide drought researchers and decision-makers to understand 1) the roles that both people and nature play as drivers of ecosystem vulnerability, 2) that ecological drought's impacts are transferred to human communities via ecosystem services, and 3) these ecological and ecosystem service impacts will feed back to both natural and human systems. In addition, our framework will help identify important trade-offs and strategies for reducing the ecological drought risks facing both human and natural systems in the twenty-first century.

\section{ECOLOGICAL DROUGHT VULNERABIL-} ITY FRAMEWORK. The drought vulnerability of an ecological community, population, individual, or process is determined by its exposure, sensitivity, and adaptive capacity (Glick et al. 2011) to reduced water availability. In the twenty-first century, each of these components of vulnerability arises from interactions between natural processes and human activities. Our novel framework clarifies these human and natural dimensions of vulnerability to highlight opportunities for mitigation of and/or adaptation to ecological drought (Fig. 1).

Ecologically available water and drought exposure. The amount of water that is ultimately available to ecosystems during a drought-ecologically available water-is influenced by a combination of natural and human-modified processes (Fig. 1). Historically, the geography, frequency, and duration of drought conditions were driven primarily by sea surface temperatures in major oceanic basins, ocean-atmosphere interactions such as El Niño-Southern Oscillation (ENSO), internal atmospheric variability, and landatmosphere feedbacks (McCabe et al. 2008; Cook et al. 2016). However, anthropogenic climate change increasingly affects the frequency, intensity, and extent of droughts (Trenberth et al. 2013), largely through higher temperatures that drive higher evaporative demand, as well as changes in precipitation type (snow versus rain) and timing, which can lead to increased dry-season length, particularly in the tropics. Climate change is also expected to increase the likelihood of multidecadal "megadroughts," which were common during some time periods in the paleorecord, but which far exceed the duration of any drought observed in the historical record (Cook et al. 2016). Similarly, the way drought spreads through a region is characterized by an interaction between natural landscape features (e.g., topography and soils) and human modifications of hydrological processes (e.g., reservoirs and irrigation) (Haddeland et al. 2014; Van Loon et al. 2016). For example, the Millennium Drought was largely driven by ENSO, but groundwater extraction and river regulation nearly doubled the reduction in river flows that led to costly ecological impacts (van Dijk et al. 2013).

Sensitivity, adaptive capacity, and natural resource management. As with drought exposure, sensitivity to ecological drought and adaptive capacity are also driven by interactions between natural and human systems. Sensitivity refers to how strongly a species or ecosystem is affected by drought exposure and results from a combination of the basic life history traits and physiology of species, population/community structure (e.g., demographics and diversity), and ecosystem-level processes (Glick et al. 2011). Adaptive capacity is the ability to accommodate or cope with the effects of drought-for example, by plants exhibiting phenotypic plasticity or animals moving to a new location in response to reduced ecological water supply (Fig. 1). These aspects of vulnerability are important because variability in a system's sensitivity and ability to adapt can cause different drought responses to the same water deficit. For example, variations in mortality patterns in southwestern U.S. piñon-juniper woodlands exposed to the severe drought of 2002/03 were driven by interactions between plant water-use traits, stand characteristics, and bark-beetle infestation (i.e., variable sensitivity) (McDowell et al. 2008). Similarly, differences in genetic diversity of European silver fir (i.e., variable adaptive capacity) determine whether a population's growth is tightly controlled by drought or largely unaffected by it (Bosela et al. 2016). Humans can influence drought sensitivity and adaptive capacity through natural resource management actions that manipulate these ecological and evolutionary characteristics (Fig. 1). For example, research in forests shows that drought-induced tree mortality is higher in denser stands and points toward reducing basal area as a management strategy to reduce vulnerability of some forested ecosystems to drought (Bradford and Bell 2017). This strategy can be accomplished through silvicultural thinning or, for some species, through prescribed fire (van Mantgem et al. 2016). 
UNDERSTANDING DROUGHT IN COUPLED NATURAL-HUMAN SYSTEMS. Types

of ecological drought. Historically, droughts were natural events that shaped ecological processes and evolutionary adaptations. Yet, changing conditions in the twenty-first century are resulting in an increased risk of megadisturbances-that is, widespread disturbances that overwhelm the adaptive capacity of ecosystems and human communities, leading to important ecological changes and ecosystem service losses (Millar and Stephenson 2015). Drought impacts cover a wide spectrum of severity, from small-scale, temporary responses (e.g., reduced productivity in plants or increased dehydration stress in wildlife) to widespread and persistent ecosystem transformations (e.g., vegetation type conversion or species range shifts). Our definition of ecological drought aims to exclude the small-scale, short-term effects within a system's adaptive capacity that fail to leave an ecological or social footprint (Fig. 2). Instead, we define ecological drought as a disturbance that pushes coupled natural-human systems beyond their adaptive capacity and triggers important socioecological feedbacks (response arrows in Fig. 1; Fig. 2).

This definition is flexible enough to include multiple types of ecological drought, differentiated based on which part of the coupled natural-human system is impacted and which set of feedbacks is triggered (Fig. 2). For example, an ecological drought may result in ecological impacts that feed back to alter natural systems-selection of drought-adapted traits or species, range shifts, or ecoclimatic teleconnections (e.g., Stark et al. 2016) - with little influence on the ecosystem services provided (type I). Alternatively, an ecological drought may produce only minor ecological effects that do not feed back to natural systems

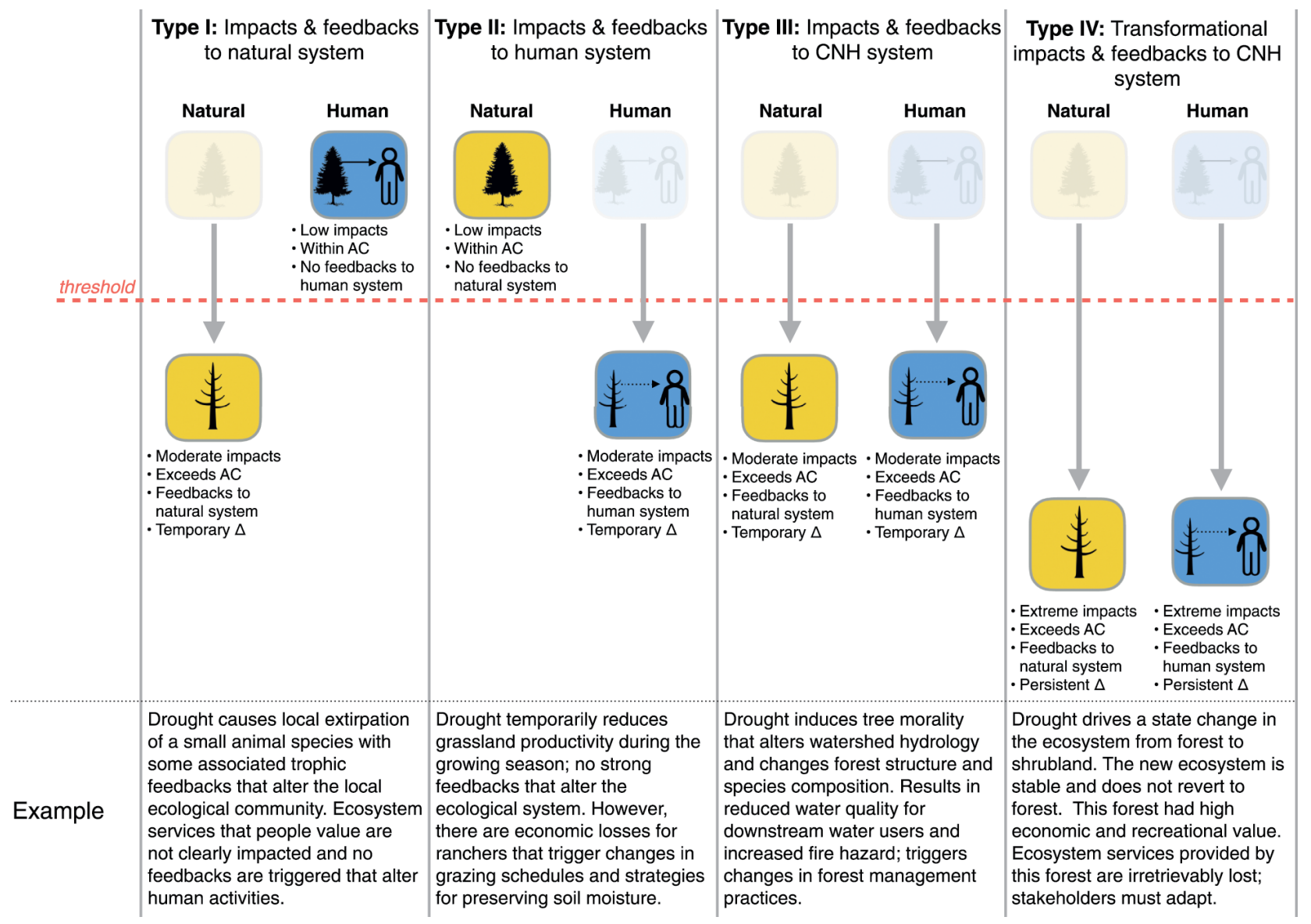

FIG. 2. Types of ecological drought are differentiated by which side of the coupled natural-human system crosses a threshold (as in Fig. I) and experiences the strongest impacts and feedbacks. Ecological impacts (yellow) feed back to the natural system and ecosystem service losses (blue) feed back to the human system; $\mathrm{AC}=$ adaptive capacity, $\mathrm{CNH}=$ coupled natural-human. 
but result in larger effects on ecosystem services that alter connected human systems (type II). A third type of ecological drought is defined by impacts and feedbacks in both human and natural systems (type III). Our definition also includes transformational ecological droughts (type IV), where ecological impacts and ecosystem service losses are extreme and drive a persistent state change in human and natural systems, such as vegetation type conversion or mass human migrations (e.g., the Dust Bowl migration).

The importance of ecosystem services. A focus on ecosystem services allows us to better
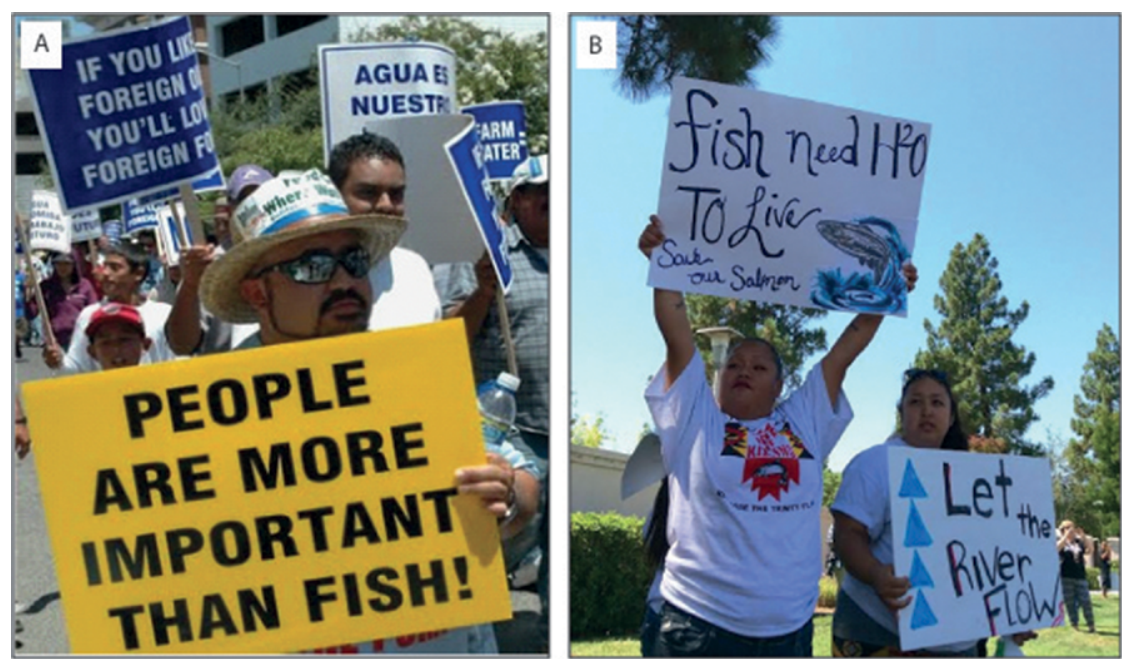

Fig. 3. Reframe the people vs nature debate. (a) Agricultural workers in California's Central Valley march in protest of state legislative action to reduce water diversions and protect endangered fish populations. (b) Advocates for the Klamath and Trinity Rivers demand the release of reservoir water slated for Central Valley irrigators in order to prevent a drought-induced fish kill (Sacramento, 2014). (Photo credits: (a) www.redstate.com, (b) https:// lostcoastoutpost.com.) appreciate that ecological im-

pacts of drought also have important implications for human communities. Pederson et al. (2006) identified that ecological impacts from drought in mountainous areas of the western United States can affect a variety of ecosystem services including provisioning (e.g., declining fisheries), cultural (e.g., reduced forestrelated tourism), and regulating (e.g., increased threat and cost of fires and pest outbreaks) services. In the twenty-first century, we increasingly understand that ecosystem services are linked to human well-being and, as a result, are beginning to address disparate problems like poverty and biodiversity conservation with innovative mutually beneficial solutions for nature and people (Guerry et al. 2015). However, drought and its acute risks to both nature and people can sometimes challenge this progress and create situations where ecosystem and human water needs are viewed as competing demands for a limited resource (Fig. 3). This perspective can cause us to ignore interdependence of ecosystems and human well-being and thus bypass potential, mutually beneficial solutions.

Our framework for ecological drought encourages an integrated approach to considering human and ecosystem water needs that relies on the concept of ecosystem services to better understand drought impacts and highlight potential strategies for integrative drought management. Such an approach corrects the "nature vs. people" misperception because it explicitly integrates human and ecological values and emphasizes identification of innovative solutions with the potential for mutual benefits.

A CALL TO ACTION. Our framing of ecological drought highlights opportunities to mitigate the risks of drought to both nature and people. But, efforts by drought researchers and decision-makers are needed to operationalize the concepts presented here. Researchers can use our vulnerability framework to evaluate the relative roles of exposure, sensitivity, and adaptive capacity, as well as parse out human versus natural drivers of ecosystem vulnerability to drought. This exercise can be useful in linking ecological drought impacts to the most relevant drivers in a given system, which can lead to more targeted and effective management strategies. Our framework also encourages decision-makers to use an ecosystem-servicesbased approach when considering trade-offs between human and ecosystem water needs in drought policy and management and may help identify strategies that are mutually beneficial.

There is a current groundswell of ecological drought research and synthesis, with important discoveries regarding the drivers of ecological drought impacts, especially the role of hotter, climate-changedriven droughts and interacting disturbances (e.g., Allen et al. 2015; Millar and Stephenson 2015; Vose 
et al. 2016). However, the effects of human water and land use on environmental water supplies are not always considered in current ecological drought research, monitoring, or prediction. The relative importance of natural climate variability, climate change, and direct human influences on environmental water supplies are likely to vary across regions and ecosystems, with the direct human influences outweighing the role of climate change in some situations (Haddeland et al. 2014). This argues for the need to focus more research on quantifying and separating these aspects of drought exposure.

Additionally, the ecological characteristics that most influence drought sensitivity and adaptive capacity, as well as how proactive and anticipatory resource management can target these traits to reduce drought vulnerability ahead of a drought needs to be more fully investigated. A growing body of literature linking life history, physiology, and other functional traits to drought sensitivity in forests (Anderegg et al. 2016), shrublands (Venturas et al. 2016), and aquatic ecosystems (Lytle and Poff 2004) provides useful examples for other systems. Recent work has built upon this ecological knowledge to show that direct manipulation of ecological characteristics can reduce vulnerability to ecological drought through strategies like prescribed fire and forest thinning (e.g., van Mantgem et al. 2016; Bradford and Bell 2017). But, this field of study needs to keep expanding to determine which ecosystems and at what scales (temporal and spatial) these kinds of proactive preparedness strategies are most effective.

Currently, research rarely integrates all aspects of ecological drought vulnerability simultaneously. Therefore, research that characterizes the human and natural dimensions of exposure, sensitivity, and adaptive capacity are needed to attribute the causes of ecological impacts and their social implications. As a start, researchers can use our framework and types of ecological drought as guides to develop questions and conduct research that determines where the greatest vulnerability lies in a given system and, therefore, which strategies may be most effective. Advancing ecological drought research in these directions will help decision-makers identify proactive strategies that can directly lead to effective, place-based management for reducing vulnerability to droughts of the future.

Mitigating the impacts of ecological drought may be possible through various changes to policies, management practices, and water infrastructure. However, these attempts to change human institutions will be more effective if there is a fundamental understanding of the interdependence of human well-being and ecosystem services. There are currently few organized efforts to categorize or quantify the ecosystem services affected by drought (see van Dijk et al. 2013). However, recent work in drought-prone areas in Australia (Banerjee et al. 2013) and the southwestern United States (Raheem et al. 2015) may serve as excellent starting places for strengthening our understanding of how ecological drought influences the goods and services people value and how those values vary through space and time. Considering the value of ecosystem services at the outset of the planning process can integrate human and natural water needs and move us forward with the understanding that an investment in water for nature may ultimately be an investment in water for people.

Acting on these mutually beneficial solutions requires a focus on drought adaptation-that is, actions taken to proactively reduce drought risk over short or long time scales. Ecological drought vulnerability may be successfully reduced through proactive natural resource management strategies (e.g., thinning the forest) or strategies that work with and support natural processes, rather than employing engineered solutions that may degrade natural systems (e.g., high-elevation reservoirs). For example, in the Amazon, reducing deforestation would reduce the ecoclimatic teleconnections that increase drought in the region (e.g., Stark et al. 2016) and could result in benefits to hydropower generation while simultaneously reducing drought-induced tree mortality. As another example, in western North America, beaver reintroduction is a drought adaptation strategy that builds upon the natural role that these mammals play in modifying hydrology in streams and wetlands (Pollock et al. 2014). Reintroducing beaver, or mimicking their structures, is a viable technique for restoring the natural water storage capacity of the landscape-thereby reducing drought exposurefor the benefit of both ecological and agricultural systems. Such strategies, often referred to as "naturebased solutions," are investments in protecting and restoring natural systems but also hold promise for reducing risks associated with ecological drought. However, such approaches are currently underutilized in the drought arena and their efficacy and cost is rarely quantified or compared to infrastructurebased mitigation techniques (Jones et al. 2012).

Changing laws and policies that guide human modifications to water flows is another action that 
could benefit both people and nature, particularly where human modifications contribute the most to ecological drought. New policies that reallocate water to the environment during times of low streamflow have proven successful, if sometimes difficult to achieve. A prime example of this success is in Australia's Murray-Darling basin when during the Millennium Drought, the proportion of flows diverted for agriculture increased dramatically, with a disproportionate impact on the environment. Lakes and rivers acidified, lagoons salinized, and the diversity of invertebrates, fish, and birds declined. In response to this crisis, an active water market using price signals and government purchase of water rights from irrigators, facilitated reallocation of water from irrigated agriculture to the environment, and despite a $70 \%$ fall in water extraction, the gross value of irrigated agricultural production remained relatively constant through the Millennium Drought (Grafton et al. 2013). Well-functioning water markets require strong legal and institutional underpinnings and are more likely to be successful at benefitting both nature and people when an ecosystem services approach is used to evaluate the trade-offs between consumptive and ecological water needs.

It is time for ecosystems to have a seat at the drought decision-making table. It is also time for ecology to recognize the importance of human decisions and well-being to the ecological drought picture. To encourage these changes, we have offered an integrative definition and framework of ecological drought to advance our scientific understanding of drought in the twenty-first century, highlight trade-offs between human and ecosystem water needs, and shape innovative policies and actions aimed at managing the rising risk of drought in coupled natural-human systems.

ACKNOWLEDGMENTS. This research was conducted by the Ecological Drought expert working group supported in part by the U.S. Geological Survey under Grant/Cooperative Agreement G15AC00277 and by the Science for Nature and People Partnership (SNAPP)-a partnership of The Nature Conservancy, the Wildlife Conservation Society, and the National Center for Ecological Analysis and Synthesis (NCEAS) at the University of California, Santa Barbara. This manuscript improved after thoughtful comments by Craig Allen and two anonymous reviewers. We thank Bill Dennison and Simon Costanzo from the Integration and Application Network for comments on Fig. 2. Use of trade or firm names is for descriptive purposes only and does not constitute endorsement of any product or service by the U.S. government. We dedicate this paper to Dr. Kelly Redmond, whose insights and thoughtful perspectives first inspired our conceptualization of ecological drought. His work, generosity, and prescient insights continue to inspire work on this topic, and many others. He will be missed.

\section{FOR FURTHER READING}

Allen, C. D., D. D. Breshears, and N. G. McDowell, 2015: On underestimation of global vulnerability to tree mortality and forest die-off from hotter drought in the Anthropocene. Ecosphere, 6, 129, https://doi .org/10.1890/ES15-00203.1.

Anderegg, W. R., T. Klein, M. Bartlett, L. Sack, A. F. Pellegrini, B. Choat, and S. Jansen, 2016: Meta-analysis reveals that hydraulic traits explain cross-species patterns of drought-induced tree mortality across the globe. Proc. Natl. Acad. Sci. USA, 113, 5024-5029, https://doi.org/10.1073/pnas.1525678113.

Banerjee, O., R. Bark, J. Connor, and N. D. Crossman, 2013: An ecosystem services approach to estimating economic losses associated with drought. Ecol. Econ., 91, 19-27, https://doi.org/10.1016/j.ecolecon .2013.03.022.

Bosela, M., and Coauthors, 2016: Effects of post-glacial phylogeny and genetic diversity on the growth variability and climate sensitivity of European silver fir. J. Ecol., 104, 716-724, https://doi.org/10.1111/1365 $-2745.12561$.

Bradford, J. B., and D. M. Bell, 2017: A window of opportunity for climate-change adaptation: Easing tree mortality by reducing forest basal area. Front. Ecol. Environ., 15, 11-17, https://doi.org/10.1002/fee.1445.

Cook, B. I., E. R. Cook, J. E. Smerdon, R. Seager, A. P. Williams, S. Coats, D. W. Stahle, and J. V. Díaz, 2016: North American megadroughts in the Common Era: Reconstructions and simulations. Wiley Interdiscip. Rev. Climate Change, 7, 411-432, https://doi .org/10.1002/wcc.394.

Glick, P., B. A. Stein, and N. A. Edelson, 2011: Scanning the conservation horizon: A guide to climate change vulnerability assessment. National Wildlife Federation Publ., 168 pp., www.nwf.org/ /media/pdfs /global-warming/climate-smart-conservation/nwf scanningtheconservationhorizonfinal92311.ashx.

Grafton, R. Q., and Coauthors, 2013: Global insights into water resources, climate change and governance. Nat. Climate Change, 3, 315-321, https://doi.org/10.1038 /nclimate1746.

Guerry, A. D., and Coauthors, 2015: Natural capital and ecosystem services informing decisions: From 
promise to practice. Proc. Natl. Acad. Sci. USA, 112, 7348-7355, https://doi.org/10.1073/pnas.1503751112.

Haddeland, I., and Coauthors, 2014: Global water resources affected by human interventions and climate change. Proc. Natl. Acad. Sci. USA, 111, 3251-3256, https://doi.org/10.1073/pnas.1222475110.

Jiang, X., and Coauthors, 2013: Projected future changes in vegetation in western North America in the twentyfirst century. J. Climate, 26, 3671-3687, https://doi .org/10.1175/JCLI-D-12-00430.1.

Jones, H. P., D. G. Hole, and E. S. Zavaleta, 2012: Harnessing nature to help people adapt to climate change. Nat. Climate Change, 2, 504-509, https://doi.org/10.1038 /nclimate1463.

Lytle, D. A., and N. L. Poff, 2004: Adaptation to natural flow regimes. Trends Ecol. Evol., 19, 94-100, https:// doi.org/10.1016/j.tree.2003.10.002.

McCabe, G. J., J. L. Betancourt, S. T. Gray, M. A. Palecki, and H. G. Hidalgo, 2008: Associations of multi-decadal sea-surface temperature variability with US drought. Quat. Int., 188, 31-40, https://doi .org/10.1016/j.quaint.2007.07.001.

McDowell, N., and Coauthors, 2008: Mechanisms of plant survival and mortality during drought: Why do some plants survive while others succumb to drought? New Phytol., 178, 719-739, https://doi .org/10.1111/j.1469-8137.2008.02436.x.

Millar, C. I., and N. L. Stephenson, 2015: Temperate forest health in an era of emerging megadisturbance. Science, 349, 823-826, https://doi.org/10.1126/science .aaa9933.

Pederson, G. T., S. T. Gray, D. B. Fagre, and J. Graumlich, 2006: Long-duration drought variability and impacts on ecosystem services: A case study from Glacier National Park, Montana. Earth Interact., 10, https:// doi.org/10.1175/EI153.1.

Pollock, M. M., T. J. Beechie, J. M. Wheaton, C. E. Jordan, N. Bouwes, N. Weber, and C. Volk, 2014: Using beaver dams to restore incised stream ecosystems. BioScience, 64, 279-290, https://doi.org/10.1093/biosci /biu036.

Raheem, N., and Coauthors, 2015: A framework for assessing ecosystem services in acequia irrigation communities of the Upper Río Grande watershed.
Wiley Interdiscip. Rev. Water, 2, 559-575, https://doi .org/10.1002/wat2.1091.

Redmond, K. T., 2002: The depiction of drought: A commentary. Bull. Amer. Meteor. Soc., 83, 1143-1147, https://doi.org/10.1175/1520-0477(2002)083<1143:TD ODAC>2.3.CO;2.

Stark, S. C., and Coauthors, 2016: Toward accounting for ecoclimate teleconnections: Intra- and intercontinental consequences of altered energy balance after vegetation change. Landscape Ecol., 31, 181-194, https://doi.org/10.1007/s10980-015-0282-5.

Trenberth, K. E., A. Dai, G. van der Schrier, P. D. Jones, J. Barichivich, K. R. Briffa, and J. Sheffield, 2013: Global warming and changes in drought. Nat. Climate Change, 4, 17-22, https://doi.org/10.1038 /nclimate2067.

van Dijk, A. I. J. M., H. E. Beck, R. S. Crosbie, R. A. M. de Jeu, Y. Y. Liu, G. M. Podger, B. Timbal, and N. R. Viney, 2013: The Millennium Drought in southeast Australia (2001-2009): Natural and human causes and implications for water resources, ecosystems, economy, and society. Water Resour. Res., 49, 10401057, https://doi.org/10.1002/wrcr.20123.

Van Loon, A. F., and Coauthors, 2016: Drought in the Anthropocene. Nat. Geosci., 9, 89-91, https://doi .org/10.1038/ngeo2646.

van Mantgem, P. J., A. C. Caprio, N. L. Stephenson, and A. J. Das, 2016: Does prescribed fire promote resistance to drought in low elevation forests of the Sierra Nevada, California, USA? Fire Ecol., 12, 13-25, https://doi.org/10.4996/fireecology.1201013.

Venturas, M. D., E. D. MacKinnon, H. L. Dario, A. L. Jacobsen, R. B. Pratt, and S. D. Davis, 2016: Chaparral shrub hydraulic traits, size, and life history types relate to species mortality during California's historic drought of 2014. PLoS One, 11, e0159145, https://doi .org/10.1371/journal.pone.0159145.

Vose, J. M., J. S. Clark, C. H. Luce, and T. Patel-Waynand, 2016: Effects of drought on forests and rangelands in the United States: A comprehensive science synthesis. U.S. Department of Agriculture General Tech. Rep. WO-93b, 289 pp., www.fs.fed.us/sites/default/files /DROUGHT_book-web-1-11-16.pdf. 